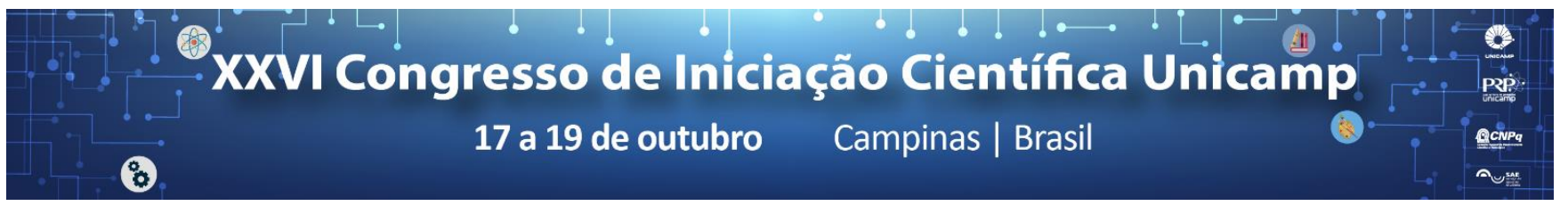

\title{
Estudo das Emissões Otoacústicas por Produto de Distorção em Crianças e Adolescentes com Histórico de Otite média Submetidas à Mirigotomia
}

\section{Luisa F. Bertazolli*, Caroline Donadon, Letícia R. Borges, Milaine D. Sanfins, Maria Francisca Colella-Santos Curso de Fonoaudiologia-DDHR-FCM \\ Resumo}

Este trabalho buscou analisar os resultados da avaliação das Emissões Otoacústicas Evocadas Produto de Distorção (EOAPD) em indivíduos com histórico de otite média secretora (OMS) que foram submetidos à intervenção cirúrgica para inserção de tubo de ventilação bilateralmente, com o objetivo de investigar o impacto à longo prazo da otite média de repetição para o sistema auditivo periférico. Houve ausência de resposta nas EOAPD e amplitudes de resposta menos expressivas em todas as frequências, em comparação ao grupo sem antecedentes de otite média, sendo que foi constatada diferença estatisticamente significativa entre os grupos.

\section{Palavras-chave:}

Otite média, emissões otoacústicas, miringotomia.

\section{Introdução}

A otite média secretora (OMS) acomete dois terços das crianças que apresentam, pelo menos, um episódio dessa afecção nos seus primeiros cinco anos de vida, sendo esta uma das doenças mais comuns na infância. Alguns estudos já demonstraram que essa condição de orelha média pode gerar pequenos danos (mas irreversíveis) à própria orelha média e/ou à cóclea. Sendo assim, este trabalho objetivou estudar as emissões otoacústicas em crianças e adolescentes com histórico de OMS de repetição, teste que avalia o estado funcional da cóclea (células ciliadas externas) e também é influenciado pelas condições funcionais das orelhas externa e/ou média. Pretendemos investigar se houve impacto da OMS de repetição na infância para o sistema auditivo periférico.

\section{Resultados e Discussão}

Este projeto foi aprovado pelo Comitê de Ética em Pesquisa da UNICAMP, pelo parecer 끙 889.074/2014. A amostra foi composta por 100 escolares de 8 a 16 anos reunidos em dois grupos:

grupo controle (GC) composto por 50 sujeitos que não apresentam história de doença otológica e grupo estudo (GE) com 50 sujeitos com antecedentes de otite de repetição na infância, que foram submetidos à cirurgia de miringotomia para inserção de tubo de ventilação (MTV) bilateralmente. Os critérios de inclusão para ambos os grupos foram otoscopia normal e avaliação audiológica básica dentro dos limites de normalidade no momento da avaliação. Foi considerado EOAPD presentes quando a relação sinal/ruído foi igual ou superior a 6 dBNPS em pelo menos três frequências, além de reprodutibilidade geral $\geq 50 \%$ e estabilidade da sonda $\geq 70 \%$. Para análise estatística dos dados foi utilizado modelos lineares generalizados. $O$ teste de efeitos utilizou a distribuição $F$-snedecor. Foi considerado efeito de grupo quando o $p$ valor foi menor do que o nível de significância de $5 \%$. Foi encontrado presença de respostas de todos os sujeitos do GC. No GE houve ausência de respostas das EOAPD em 9 orelhas. Ao analisar as médias das amplitudes de resposta das EOAPD, constatamos que o GE apresentou menores valores, em todas as frequências, quando comparado com o GC. Houve diferença estatisticamente significante entre os grupos, o que sugere que a OMS de repetição pode levar a pequenas disfunções subclínicas detectadas no exame de EOAPD e que podem interferir no mecanismo de amplificação coclear.

\section{Conclusões}

O antecedente de OMS de repetição nos 6 primeiros anos de vida interferiu de forma negativa nas respostas das EOAPD que se revelou sensível e eficaz para detectar mínimas mudanças que podem ocorrer no sistema auditivo periférico de quem apresentou episódios de otite média de repetição. Conhecendo os efeitos a curto e longo prazo da OMS de repetição, com impacto na audição, esta pesquisa reafirma a necessidade de monitorar a otite na primeira infância, mesmo na presença de audiograma dentro dos limites de normalidade, de modo a reduzir os efeitos adversos e irreversíveis desta.

\section{Agradecimentos}

Este trabalho foi financiado pelo PIBIC/CNPq.

Borges, L.R.; Paschoal J.R.; Collela-Santos M.F. (Central) Auditory Processing: the impact of otitis media. Clinics (Sao Paulo). 2013 July; 68(7): 954-959. Campos U.P., Sanches S.G., Hatzopoulos S, et al. Alteration of distortion product otoacoustic emission input-output functions in subjects with a previous history of middle ear dysfunction. Med Sci Monit. 2012;18(4):MT27-31.
Kay DJ, Nelson M, Rosenfeld RM. Meta-analysis of tympanostomy tube sequelae. Otolaryngol - Head NeckSur. 2001;124(4):374-80.

Klausen O, Moller P, Holmefjord A, Reisaerter S, Asbjornsen A. Lasting effects of otitis media with effusion on language skills and listening performance. Acta Otolaryngol Suppl 2000;543:73-6.

Yilmaz, S; et al. Otoacoustic emissions in Young adults with a history of otitis media. J Laryngol Otol. 2006;120(2):103-7. 